\title{
AS REGIÕES BRASILEIRAS E O NOSSO PATRIMÔNIO: EXPERIÊNCIA DE EDUCAÇÃO PATRIMONIAL
}

\author{
Ana Paula Ferreira ${ }^{1}$
}

\section{INTRODUÇÃO}

A presente pesquisa é um estudo de caso apresentando ação de educação patrimonial em duas turmas de $5^{\circ}$ ano numa escola pública na cidade de Poços de Caldas (MG), detalhando-se os procedimentos, metodologias de ensino e resultados do empreendimento pedagógico. A importância situa-se na divulgação de estratégias pedagógicas desenvolvidas no decorrer do ano letivo que induziram a preservação patrimonial e ao sentimento de coletividade e responsabilidade sobre o ambiente. Objetiva-se, assim, detalhar as atividades trabalhadas nessas turmas, mostrar o impacto pedagógico e valorizar experiências que contribuem para a criação de sentido entre patrimônio e comunidade.

\section{METODOLOGIA}

A pesquisadora no ano de 2010 era professora de duas turmas de $5^{\circ}$ ano numa escola pública do munícipio de Poços de Caldas e desenvolveu o projeto pedagógico "As regiões brasileiras e o nosso patrimônio".

Tendo em vista que o currículo de Geografia no 5a ano contempla o estudo sobre as regiões brasileiras, buscou-se fazer um panorama desses espaços e seus respectivos patrimônios, sejam eles imateriais ou materiais, numa relação de entendimento entre o local e o nacional, o que é geralmente marginalizado e o que é preservado, memória e esquecimento, sugerindo aos estudantes para além da ação de preservação, mas de observação sobre a questão do poder e a manutenção de determinada memória.

As atividades elaboradas pelos estudantes resultaram em textos produzidos, cartas a órgãos responsáveis pela manutenção, fotografias tiradas pelos

\footnotetext{
${ }^{1}$ Mestranda Universidade Federal de Alfenas (Unifal) e supervisora pedagógica do Estado de Minas Gerais. Endereço eletrônico: anapaulakarenina@yahoo.com.br
} 
próprios estudantes e comparação crítica entre o patrimônio público do bairro e a área central.

Por isso, antes de tudo, cabe situar o ponto de partida: a cidade e o bairro.

\section{CENÁRIO DA PESQUISA}

Poços de Caldas é uma cidade do sul de Minas Gerais agraciada com águas sulfurosas, que atraíram pecuaristas e pessoas em busca de cura através da água termal. As águas hidrominerais agradavam o gado e em torno delas também cresceu a propaganda de suas qualidades medicinais para tratamento de feridas e outras enfermidades (SOUZA, 2015)

Alguns banhistas construíram ranchos improvisados próximos às fontes de águas termais e com o aumento cada vez mais gradativo de visitantes, as autoridades políticas entenderam a importância de o local ser delimitado para se proporcionar acesso aos enfermos que procuravam as águas para a cura de suas doenças. Desta forma,

\footnotetext{
Aproveitando-se da disposição da Lei no 1.741, de 8 de outubro de 1870, (A Assembleia Provincial) mandou o procurador fiscal Antônio Luiz Maria Soares de Albergaria desapropriar os terrenos por utilidade pública. O mais feliz dos resultados coroou esta missão; pois que os posseiros Junqueira, e sua família fizeram doação gratuita à Província de 96 hectares e 8 décimos de terras em torno dos poços. Os terrenos doados têm proporção para a fundação de uma grande cidade, com logradouro público. (OTONNI, 1960, p. 108 In SOUZA, 2015, p. 57).
}

Tendo em vista que a abordagem positivista da história foi a pedra de toque durante muitos anos, transmitida na escola como modelo de verdade e de probidade a história dos vencedores em Poços de Caldas não foi diferente. A família Junqueira revestida de prestígio econômico e autoridade política alcançou altos índices de notoriedade pública desde o vínculo de seu sobrenome a fundação da cidade, perpassando pela disputa de poder em torno da administração da cidade (MEGALE, 2002). A cristalização da sua história concatenada com a história da cidade, fortalecendo a memória deste pequeno grupo, está em diversos patrimônios da cidade que recebem nomes de membros desta família. 
O poder na cidade de Poços de Caldas não se manifesta apenas na valorização de uma memória centralizada em poucas famílias, mas na sua organização e estrutura que foi elaborada para atender prioritariamente aos turistas e parcamente aos moradores, principalmente aos de baixa renda.

De forma a contemplar os visitantes que vinham principalmente de São Paulo e Rio de Janeiro, as diversas gestões municipais investiram no turismo local, com construções de balneários, cassinos, praças, fontes, conservação de calçadas da região central e manutenção dos espaços públicos que eram frequentados por turistas.

Em contrapartida, boa parte dos moradores com baixa renda mora em casas afastadas do centro da cidade em bairros de casas populares e com pouca presença do Estado. Dois desses bairros ${ }^{2}$ foram o alvo de nossa pesquisa haja vista serem os locais onde moram as crianças atendidas pela na qual a pesquisadora desenvolveu seu trabalho.

A comunidade é constituída de trabalhadores que, em sua maioria, precisam acordar mais cedo que o costume dos moradores do centro, atravessar a cidade em coletivos lotados e voltar à noite. A presença de uma empresa multinacional, cuja estrutura propiciou a origem dos bairros, é outra fonte de renda para outros tantos moradores, seja como funcionários efetivos ou terceirizados, que muitas vezes vieram de outros estados para trabalharem na corporação.

No ano de 2010, período em que foi efetuado o projeto "As regiões brasileiras e o nosso patrimônio", o bairro tinha parcos equipamentos públicos. Os que existiam eram depredados e não havia a manutenção por parte dos órgãos gestores. Algumas ruas eram de terra, o que era um transtorno em época de chuva, e as calçadas cheias de buracos ou intransponíveis, o que obrigou que os pedestres usassem a rua para transitarem. No caso do bairro II, na época havia apenas o posto de saúde, uma estação de tratamento de esgoto e uma praça. Não havia sido concluída creche, não tinha parquinho, nem academia ao ar livre e os moradores que sofriam com a enchente não tinham sido deslocados ainda. $O$ bairro é comumente conhecido pela sua vulnerabilidade a alagamentos e enchentes no período de chuva, dadas as condições de várias casas construídas próximas ao córrego que corta o bairro. Outro problema que vem a ser um dos motivos para isso

\footnotetext{
${ }^{2}$ Nomeados, aqui, como bairros I e II.
} 
ocorrer é a grande presença de lixo nas ruas, que durante as chuvas entope os bueiros ou é levado pela enxurrada para o córrego, que fica exposto ao céu aberto com o lixo nas suas margens, tendo em vista que a coleta de lixo não era realizada em determinadas ruas.

Nesse caos de infraestrutura agravam-se os problemas de patrimônio ambiental, seja porque a população usa os córregos como vias de eliminar o lixo ou pela ausência de calçadas, o que não possibilita o plantio de árvores:

Os moradores da periferia, uma vez desatendidos em suas demandas urbanas básicas, singularizam-se e tornam-se poluidores potenciais: a inexistência de coleta de lixo regular e de boa qualidade obriga-os a servirem-se dos córregos como sumidouros de seus dejetos. 0 parcelamento irregular dos lotes, assim como a inexistência de calçadas, dificulta e desestimula a arborização de vias. (MOURA; ULTRAMARI, 1996)

Pensar nosso espaço, desde o nível local até chegar ao nacional e fazer esse "retorno", é uma alternativa para se pensar em possibilidades de mudanças, frente aos problemas vivenciados pelas comunidades dos bairros I e II. Problemas esses de marginalização próprios de áreas periféricas, onde a assistência de políticas públicas é mínima e a degradação patrimonial é um problema grave.

A questão do patrimônio não poderia ficar de fora, seja porque participa do espaço e se faz através dele, seja porque membros da comunidade participam de depredações do patrimônio existente, pichando as paredes da quadra, quebrando portas da escola, jogando lixo no chão. Pensar numa outra modalidade do bairro é pensar, inclusive, em sua valorização e cuidado e, portanto, isso esbarra no quesito patrimonial.

\section{UMA EXPERIÊNCIA DE EDUCAÇÃO PATRIMONIAL}

Patrimônio, em sua origem etimológica, designa tudo aquilo que foi herdado do pai da família. Contudo, na Roma Antiga, patrimônio era conotado à propriedade privada e não havia a definição de patrimônio público. Esse conceito veio a surgir com o advento da Revolução Francesa e a formação de novos Estados. Nesse novo cenário era necessária a formação de cidadãos que comungassem de uma mesma língua, defendessem uma cultura, incorporassem sentimentos civis e 
de pertencimento a uma nação. Diante disso, a compreensão de patrimônio como um legado de todo um povo começa a apontar. (FUNARI, PELEGRINI, 2006)

Foi dentro desse conceito de patrimônio, como algo coletivo e herdado de gerações anteriores, que a professora trabalhou. Apresentou a palavra dicionarizada e um breve texto elaborado pela docente, com linguagem de fácil acesso, e convidou o responsável pelo museu da cidade a expor sobre o assunto. Após essas atividades os alunos escreveram um breve relatório do que entenderam e cabe citar um trecho do texto de uma das alunas: "Patrimônio é ponto turístico, arte, estátua, fonte, igreja antiga, lazer, mas se as pessoas não colaborarem todas saem perdendo, até quem não estragou".

Com o objetivo de que compreendessem que patrimônio não é somente o ponto turístico, mas inclusive o que desfrutam cotidianamente, a professora refletiu com os alunos a importância do patrimônio, quem é beneficiado, por que há patrimônio com uma maior proteção do Estado e outros não, e como delimitarmos o que é necessário preservar. Em relação a esse último tópico, os estudantes chegaram à conclusão que é primordial preservar aquilo que faz sentido para um grupo e concordaram que a escola era um espaço que deve ser preservado.

A partir dessa constatação os estudantes foram a campo, observando e anotando o que thes chamava a atenção sobre algum problema enfrentado pelos estudantes diante de uma ausência de cuidado com o patrimônio escolar. A resposta não foram as pichações, nem as janelas quebradas, mas a presença de pombos no refeitório (esses animais, atraídos pela comida, se abrigaram no forro do telhado e sujavam constantemente as mesas e o chão, provocando diversos transtornos).

Tendo em vista o problema elencado, a professora levou um texto sobre doenças causadas por pombos e após leitura e debate acerca como se responsabilizariam, os alunos escreveram uma carta a Secretaria Municipal de Educação solicitando telas que cobrissem o telhado, de modo a impossibilitar a permanência dessas aves na escola.

Ressalta-se, aqui, que com essas atividades as aulas de Língua Portuguesa deixam de ser um espaço de mera memorização dos componentes gramaticais e adquire o peso da ação comunicativa, na qual os sujeitos se apropriam da linguagem para transformá-la em ferramenta de ação para um leitor real e uma demanda também real. $\mathrm{O}$ trecho da carta do estudante ilustra isso "Eu, aluno da [escola] estou com um problema no refeitório porque os pombos estão 
contaminando com suas fezes e sujando toda escola o que pode causar doenças como histoplasmose e psitacose. Gostaríamos que você tomassem providências com urgência.”.

Ao contemplarem que o poder público prontamente agiu diante da denúncia e solicitação que fizeram, os estudantes perceberam a importância de ações de cuidado para com o bairro numa ideia de cobrança das esferas competentes. Objetivando aulas que dialogassem a prática e a teoria, a professora planejou as atividades intercalando-as com o conteúdo programático do 5ㅇan ano, relacionando o local e o nacional, buscando aulas que atendessem a aproximações entre a ação e o conhecimento, entre a cidadania e o conteúdo, de maneira interdisciplinar.

A abordagem da Geografia não é de mera descrição da paisagem característica que ficou consolidada durante muito tempo - mas compreendida como estudo de um espaço que se configura com contradições, devido à divisão de classes sociais e a pluralidade cultural (MOREIRA, 1981). Em continuidade com a proposta de conflitos, a leitura que se faz em História não é a partir da perspectiva positivista, que enaltece algumas figuras da política e da economia, como se a História fosse uma linha reta, factual, determinista, de causa e efeito. As lutas e as resistências são evidenciadas, entre bandeirantes e indígenas, escravizados e portugueses, moradores do centro da cidade e da periferia, pontuando-se que a história embora se faça em boa medida enquanto registro dos vencedores, é elaborada por todos, e quanto mais nos apropriarmos da realidade, mais condições há de transformá-la (BORGES, 2007).

A abordagem em educação patrimonial, portanto, organizou-se de maneira interdisciplinar e como estratégia para a formação de cidadania, envolvendo os estudantes na leitura de mundo a começar pelo chão onde pisam, discutindo a preservação patrimonial, o poder e a preservação da periferia como mecanismo de resistência. Uma vez que o cuidado com patrimônio está diretamente associado ao sentido que determinado grupo emprega, a educação patrimonial precisa trazer à tona o sentido, relacionado à existencial coletiva (MAGALHÃES, 2009).

Por isso que durante as aulas de Geografia e História se fazia constantemente a comparação entre determinada situação em alguma região e o patrimônio local. Ao estudarem a Região Nordeste, discutia-se na época de 2010 os impactos da transposição do Rio São Francisco e a professora aproveitou esse 
conteúdo para debater o patrimônio natural do bairro, o córrego, e como a intervenção humana sobre a natureza pode ser desastrosa, ao ponto inclusive de corroborar para a enchente.

Tanto o patrimônio material como o imaterial foi apresentado, e em cada um deles é perguntado qual grupo provavelmente que elaborou, que carregou as pedras e levantou paredes, e qual grupo que usufruiu, que teve sua memória perpetuada. "Preservaram-se as igrejas barrocas, os fortes militares, as casasgrandes e os sobrados coloniais. Esqueceram-se, no entanto, as senzalas, os quilombos, as vilas operárias e os cortiços." (ORIÁ, 2006, p. 131).

Essa comparação entre patrimônios não foi feita apenas durante 0 estudo por cada região. Foi realizada, também, pelos estudantes em relação à organização da cidade de Poços de Caldas, ilustrada como uma cidade de médio porte típica da região Sudeste, que ao se industrializar, traz consigo um crescimento populacional e dos bairros, nem sempre prontos a atender os moradores.

Após um percurso pelo bairro com registro de fotos, os estudantes as compararam com os cartões postais da cidade, percebendo que historicamente grupos que estão no poder pretendem manter uma memória e esquecer outra, e que enquanto seres históricos, na condição de moradores, precisam defender o espaço em que estão como instrumento de resistência. Daí adveio outra carta, desta vez destinada a um vereador, solicitando que ele encaminhasse todas as queixas ao Executivo de toda lista de situações que foi encaminhada a ele: a necessidade da limpeza do córrego, das ruas, dos terrenos baldios e de bueiros; o conserto de telefones públicos; o asfaltamento e a manutenção de ruas; a construção de cobertura nos pontos de ônibus; a arborização das vias públicas. Junto à carta seguiu, em anexo, as fotos e as legendas identificadas pelos próprios estudantes.

O protagonismo dos estudantes foi evidenciado pelo ativismo de cobrança e denúncia e também nas produções culturais dos alunos. Uma dessas produções de marca nordestina foi a leitura e criação de cordéis. Além de recitar o cordel em frente a uma câmera para depois se auto avaliarem, os estudantes eram convidados a escrever, tal qual o trecho do cordel feito por dois estudantes "O boi da meia noite" de autoria de dois alunos, no qual contavam que: "Era uma vez/ um boi lá do Nordeste/ que não tinha muié/ Ele só andava a pé/ saía a meia noite/ com tênis 'soçaite'/ e pela noite passeava." 
Outra forma de vivenciarem uma Educação Patrimonial foi uma visita ao Instituto Cultural Moreira Salles que contava com uma exposição de fotos do "Brasil Colônia". As fotos traziam diversas informações que já haviam sido exploradas em sala de aula, e que serviram de fonte de comparação entre as roupas, trabalhos, casas dos coronéis e dos escravizados; das sinhás e das vendedoras ambulantes; do patrimônio que cada grupo se apropriava e produzia e de como o passado se transmite para o presente.

A capoeira enquanto legado de nosso patrimônio cultural foi encenada na peça de teatro "Escravidão e Resistência", texto criado pela professora. A apresentação foi no espaço cultural da Urca, um ponto turístico da cidade. Além deste ponto turístico, as crianças visitaram o Museu, o Parque José Afonso Junqueira, o Relógio Floral e o Cristo Redentor, de modo que sentissem que esses espaços também são de cada um deles.

Quando a Região Norte foi trabalhada, enfatizou-se novamente 0 patrimônio ambiental, ressaltando a beleza e a importância da vasta Floresta Amazônica que está sendo devastada em nome do lucro, trazendo enormes impactos ambientais a todos. Ao compreenderem que as árvores enquanto contribuem para a emissão de oxigênio e ainda restauram o equilíbrio da água, rios e nascentes, os estudantes novamente pensaram sobre a situação do córrego. Mediante doação de diversas mudas de árvores, os alunos prepararam cartazes chamando a atenção da comunidade sobre a falta de zelo com o bairro e saíram em passeata da escola até o córrego onde plantaram as mudas.

O assunto patrimônio é extremamente vasto e não cabe apenas em ano escolar, pois precisa ser vivido, sentido, construído. Algumas danças regionais foram apresentadas em vídeos, fez-se um dia de café com comidas típicas, estudouse a congada e os caiapós na festa tradicional de São Benedito que ocorre em Poços de Caldas no mês de maio, mas a cultura não se esgota, pois está sempre sendo formada e se renovando.

Entende-se, assim, que o objetivo maior dessa experiência em educação patrimonial não foi esmiuçar todos os patrimônios de cada região, até porque seria inviável. Mas diante desse quadro de conteúdo, estabelecer associações com o universo real dos estudantes se concretizava. Por isso, se buscou favorecer uma consciência sobre o patrimônio local, sensibilizar para o cuidado e para o protagonismo diante da percepção de que são sujeitos históricos, a 
construção de pertença e a importância do trabalho coletivo inserido em sentidos também coletivos.

\section{CONCLUSÃO}

A comparação entre os espaços, realizada durante o projeto, justifica-se não somente para mostrar discrepâncias e reflexões sobre a presença maior do Estado em certas áreas, como também de incentivar tomada de atitudes. Traçar paralelos e associações para incentivar a discussão sobre a distribuição do poder, sem fornecer bases para o contraponto é reforçar a inércia e a passividade crítica. Por isso, além de discussões e debates sobre as diferenças, os alunos também assumiram o papel de personagens principais da história do bairro e da escola. Assim, se a área central tem sua estrutura dada às pressões dos empresários, enquanto moradores do bairro precisavam valer de seus direitos pressionando as esferas políticas para a conservação e ampliação dos serviços públicos prestados.

Mediante essa experiência de educação patrimonial os estudantes foram despertados sobre a condição do patrimônio dos bairros, que embora sucateados pela esfera pública, não poderiam continuar nas mesmas condições de tratamento pelos seus moradores.

Diante da sensibilização de pertencimento e na consciência crítica sobre a questão do poder, capital, patrimônio para quem e para o quê, compreenderam o patrimônio como instrumento de legitimar uma ideologia e ao mesmo tempo de resguardar uma memória. Perceberam-se enquanto cidadãos que ao descobrirem sentidos coletivos sobre o patrimônio, precisam reivindicar ao poder público o cuidado e a manutenção, mostrando posturas de consciência, valorização, resistência e de protagonismo.

\section{REFERÊNCIAS}

BORGES, Vavy Pacheco. O que é História. São Paulo: Brasiliense, 2007.

COSTA, da Epaminondas. Manual do Patrimônio Público - Teoria e Prática. Belo Horizonte: Inédita, 1999. (p.17-23).

FERREIRA, Jurandir. Um hectare na história de Poços de Caldas. Poços de Caldas: Gráfica Brasil, 1996. 
FUNARI, Pedro Paulo; PELEGRINI, Sandra. Patrimônio Histórico e Cultural. Rio de Janeiro: Jorge Zahar Editor, 2006.

MAGALHÃES, Leandro Henrique. Educação Patrimonial: uma análise conceitual. In: II ENCONTRO CIDADES NOVAS - A CONSTRUÇÃO DE POLÍTICAS PATRIMONIAIS, 2009, Londrina. Centro Universitário Filadélfia - UniFil, 2009. p. 112

MEGALE, Nilza Botelho. Memórias Históricas de Poços de Caldas. Poços de Caldas: Sul Minas, 2002.

MOREIRA, Ruy. O que é geografia. São Paulo: Brasiliense, 1981.

MOURA, Rosa, ULTRAMARI, Clovis. O que é Periferia Urbana. São Paulo: Brasiliense, 1996.

ORIÁ, Ricardo. Memória e ensino de História. In: BETTENCOURT, Circe (Org.). 0 Saber Histórico na sala de aula. 11. ed. São Paulo: Contexto, 2006. p. 128-148.

SABALLA, Viviane. Educação Patrimonial, "Lugares de Memória". Rev. Mouseion, v. 1, p. 23-25, jun. 2007.

SOUZA, Maria José de (Tita). Reinado e poder no Sul das Minas Gerais. Belo Horizonte: Mazza, 2015. 